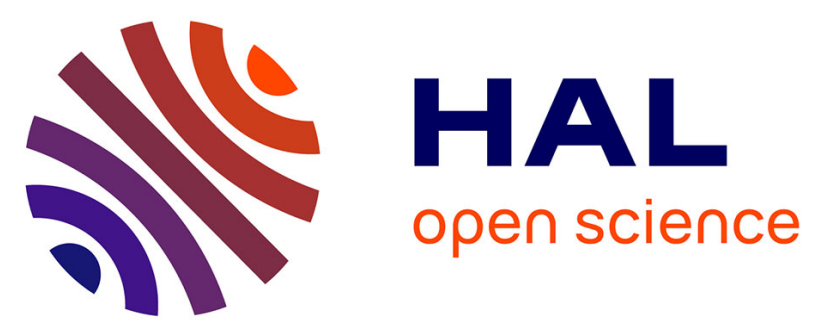

\title{
Core level shifts as indicators of Cr chemistry on hydroxylated $\alpha$-Al2O3(0001): a combined photoemission and first-principles study $\dagger$
}

Maya Messaykeh, Stéphane Chenot, Pascal David, Gregory Cabailh, Jacques Jupille, Alexey Koltsov, Pierre Lagarde, Nicolas Trcera, Jacek Goniakowski, Rémi Lazzari

\section{To cite this version:}

Maya Messaykeh, Stéphane Chenot, Pascal David, Gregory Cabailh, Jacques Jupille, et al.. Core level shifts as indicators of $\mathrm{Cr}$ chemistry on hydroxylated $\alpha$-Al2O3(0001): a combined photoemission and first-principles study†. Physical Chemistry Chemical Physics, 2021, 10.1039/D1CP03224K . hal03359564

\section{HAL Id: hal-03359564 \\ https://hal.sorbonne-universite.fr/hal-03359564}

Submitted on 30 Sep 2021

HAL is a multi-disciplinary open access archive for the deposit and dissemination of scientific research documents, whether they are published or not. The documents may come from teaching and research institutions in France or abroad, or from public or private research centers.
L'archive ouverte pluridisciplinaire HAL, est destinée au dépôt et à la diffusion de documents scientifiques de niveau recherche, publiés ou non, émanant des établissements d'enseignement et de recherche français ou étrangers, des laboratoires publics ou privés. 


\title{
Journal Name
}

ARTICLE TYPE

Cite this: DOI: $00.0000 / x x x x x x x x x x$

\section{Core level shifts as indicators of $\mathrm{Cr}$ chemistry on hydrox- ylated $\alpha-\mathrm{Al}_{2} \mathrm{O}_{3}(0001)$ : a combined photoemission and first-principles study}

\author{
Maya Messaykeh, ${ }^{a}$ Stéphane Chenot, ${ }^{a}$ Pascal David, ${ }^{a}$ Gregory Cabailh, ${ }^{a}$ Jacques Jupille, ${ }^{a}$ \\ Alexey Koltsov, ${ }^{b}$ Pierre Lagarde ${ }^{c}$ Nicolas Trcera ${ }^{c}{ }^{c}$ Jacek Goniakowski, ${ }^{a}$ and Rémi Lazzari ${ }^{* a}$
}

Received Date

Accepted Date

DOI: $00.0000 / x x x x x x x x x x$

The $\mathrm{Cr} / \alpha-\mathrm{Al}_{2} \mathrm{O}_{3}(0001)$ interface has been explored by $\mathrm{X}$-ray photoemission spectroscopy, $\mathrm{X}$-ray absorption spectroscopy (XAS) and ab initio first-principle calculations of core level shifts including final state effects. After an initial oxidation via a reaction with residual surface $\mathrm{OH}$ but no reduction of the alumina substrate, $\mathrm{Cr}$ grows in a metallic form without any chemical effect on the initially oxidized $\mathrm{Cr}$. However, $\mathrm{Cr}$ metal lacks crystallinity. Long-range (reflection high energy electron diffraction) and short-range (XAS) order are hardly observed. Photoemission combined with atomistic simulations becomes a unique tool to explore chemistry and environment at the $\mathrm{Cr}$ /alumina interface. $\mathrm{Cr} 2 \mathrm{p}$, $\mathrm{O} 1 \mathrm{~s}$ and $\mathrm{Al} 2 \mathrm{~s}$ shifted components are all explained by the formation of moieties involving $\mathrm{Cr}^{3+}$ and/or $\mathrm{Cr}^{4+}$ and of metallic $\mathrm{Cr}^{0}$, which supports the previously found $\mathrm{Cr}$ buffer mechanism for poorly adhesive metals. Beyond the situation under study, the present data demonstrate the ability of a combined experimental and theoretical approach of core-level shifts to exhaustively describe the general case of disordered metal/oxide interfaces.

\section{Introduction}

Dielectric-supported films of late transition or coinage metals $(\mathrm{Cu}, \mathrm{Zn}, \mathrm{Ag}, \mathrm{Pt}, \mathrm{Au})$ are encountered in many applications for their specific optical $1+5$, electric $\frac{67}{6}$, electronic $\frac{58}{8}$ and catalytic $^{910}$ properties. Yet, a constant concern is the poor wetting at the metal/dielectric interfaces ${ }^{11 \mid 12}$ which, even in the case of a sizeable coverage reached through kinetic effects, leads to the synthesis of inherently out-of-equilibrium films 13 .16. Layer stacks stable under operating conditions are commonly obtained through the pre-deposition of intermediate layers of early transition metals, the so-called buffers, such as $\mathrm{Ni}|1| 17, \mathrm{Ti}|2| 4|5| 8 \mid 18$, $\mathrm{Nb}^{1 / 19}$ and $\mathrm{Cr}$ 1/2/4/5]. In particular, we have focused in the recent years on the capacity of pre-deposited $\mathrm{Cr}$ to enhance the sticking, spreading and adhesion of $\mathrm{Zn}$ on $\alpha-\mathrm{Al}_{2} \mathrm{O}_{3}(0001)^{2025}$. The subject was inspired by advanced high strength steels which are alloyed with electropositive elements (including aluminium)

\footnotetext{
a CNRS/Sorbonne Université, Institut des NanoSciences de Paris, UMR 7588, 4 Place Jussieu, F-75005 Paris, France

${ }^{b}$ ArcelorMittal Maizières Research, voie Romaine, F-57280 Maizières-lès-Metz, France c Synchrotron SOLEIL, L'Orme des Merisiers, Saint-Aubin, BP 48, F-91192 Gif-surYvette, France

* Corresponding author: remi.lazzari@insp.jussieu.fr

$\dagger$ Electronic Supplementary Information (ESI) available: [Complementary figures of photoemission analysis of $\mathrm{O} 1 \mathrm{~s}$ and $\mathrm{Cr} 2 \mathrm{p}$ core levels are given in ESI.]. See DOI: 00.0000/00000000.
}

and used to lighten car weight to comply with energy saving rules. A shortcoming is that the corresponding steel grades are difficult to galvanize 2627 because, due to oxygen-induced segregation, steel sheets are covered with oxides (in particular alumina $28-30$ ) at the end of cold rolling and recrystallization annealing. In such a context, the $\mathrm{Zn} / \mathrm{Cr} / \alpha-\mathrm{Al}_{2} \mathrm{O}_{3}(0001)$ model stack is of general relevance for the study of the mechanisms at work in the buffer effect. Chromium $1 / 2477$ is representative of the class of the early transition metals often encountered in buffers and $\alpha-\mathrm{Al}_{2} \mathrm{O}_{3}(0001)$ is an archetypal non reducible oxide

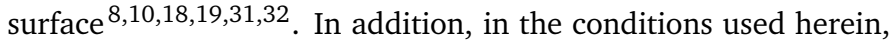
at $300 \mathrm{~K}$ in vacuum, $\mathrm{Zn}$ does not stick at all on bare alumina which eliminates any ambiguity as to the buffer effect.

The way $\mathrm{Cr}$ acts as a promoter for Zn sticking on alumina deserves attention. In the submonolayer range, $\mathrm{Cr}$ behaves as a very effective seed layer as minute metallic $\mathrm{Cr}$ amounts dramatically increase $\mathrm{Zn}$ sticking 25 . For example, a Cr coverage of $\sim 5 \%$ allows the sticking of almost an entire dose of $15 \AA$ of $\mathrm{Zn} 25$. Three-dimensional supported clusters, obtained commonly for transition metals on alumina or silica $\frac{11 \mid 12}{12}$ as demonstrated for $\mathrm{Cr} /$ alumina by optics 25 and calculations 2122 , unexpectedly become effective buffers. The mechanism contrasts starkly with the common view of buffers as continuous two-dimensional layers. Beyond a clear academic interest, such a mechanism 25 
is of prime importance in relation to applications in which (i) technical constraints exclude continuous buffer layers 1 or (ii) keeping properties of the functional layer requires reducing the buffer thickness as much as possible $\frac{15}{15}$. Because the extraordinary promotion of $\mathrm{Zn}$ sticking by minute $\mathrm{Cr}$ clusters relies on $\mathrm{Zn}$ attachment to metallic $\mathrm{Cr} 25$, the interfacial chemistry plays a pivotal role in the process. Cr clusters are not entirely metallic. Xray absorption spectroscopy (XAS) combined with first principles Density Functional Theory (DFT) calculations showed that, at the onset of its deposition, $\mathrm{Cr}$ reacts with residual $\mathrm{OH}$ groups 24 to mainly form $\mathrm{Cr}^{3+}{ }_{-} \mathrm{O}_{2} \mathrm{H}$ surface moieties while $\mathrm{Cr}$ does not reduce the alumina substrate 24 . However, the observation of reduced $\mathrm{Al}$ at the $\mathrm{Cr} / \alpha-\mathrm{Al}_{2} \mathrm{O}_{2}(\overline{1} 012)$ interface ${ }^{33} 34$ or of oxidizied $\mathrm{Cr}$ on $\mathrm{OH}$-free alumina thin film on $\mathrm{NiAl}(110) \frac{35 \mid 36}{36}$ question this finding. As the Cr film thickens, XAS 24 and UV-visible plasmonics 25 reveal a metallic behaviour but, in the absence of quantitative data, the frontier between the two media remains unclear. In particular, the formation of intermediate oxidation states at the $\mathrm{Cr} / \mathrm{Cr}-\mathrm{O}_{2} \mathrm{H}$ interface cannot be excluded.

To establish on which chemistry the $\mathrm{Zn} / \mathrm{Cr} / \mathrm{Al}_{2} \mathrm{O}_{3}$ seed mechanism is relying, the present work aims at analysing all the elements involved at the $\mathrm{Cr} / \alpha-\mathrm{Al}_{2} \mathrm{O}_{3}(0001)$ interface by photoemission. A comprehensive analysis of the $\mathrm{Cr} 2 \mathrm{p}, \mathrm{O} 1 \mathrm{~s}$ and Al 2s core level shifts is performed, including those induced by the contact at the metal/oxide interface in the absence of any chemical bond. Film crystallinity and ordering are analysed via XAS oscillations at the Cr K-edge and electron diffraction. In an original way, photoemission data are supplemented by ab initio calculations of core-level shifts prior to checking the consistency of the findings with the previous analysis of the same system $24 \mid 25$.

\section{Methods}

\subsection{Experimental}

X-ray photoemission spectroscopy (XPS) was performed in an ultra-high vacuum (UHV) vessel composed of a preparation (base pressure of $2.10^{-10}$ mbar) and an analysis chamber $\left(5.10^{-11}\right.$ mbar) 25 . XPS was recorded under Al-K $\alpha$ or $\mathrm{Mg}-\mathrm{K} \alpha$ non-monochromatic excitation with an hemispherical analyser (Phoibos 100 from SPECS; delay line detector) at a pass energy of $20 \mathrm{eV}$ or $50 \mathrm{eV}$ in a normal emission configuration. No charge compensation was applied. Spectra were referenced to tabulated $\mathrm{Al} 2 \mathrm{~s}$ binding energy $\left(E_{B}\right)$ in $\mathrm{Al}_{2} \mathrm{O}_{3}\left(E_{B}=119.6 \mathrm{eV}\right)$ 37. Film thicknesses were estimated by taking the ratio of substrate $(\mathrm{O} 1 \mathrm{~s}$ and $\mathrm{Al} \mathrm{2s}$ ) and deposit (Cr 2p) core level areas obtained after subtraction of a Tougaard background ${ }^{38}$ with $B=3006 \mathrm{eV}^{2}$ and $C=1643 \mathrm{eV}^{2}$ parameters and after correction from analyser transmission function and photoionization cross sections ${ }^{39}$ (see supplementary information of Ref. 25). To quantify thin $\mathrm{Cr}$ films, the second plasmon satellite of $\mathrm{O} 1 \mathrm{~s}$ was subtracted from the $\mathrm{Cr} 2 \mathrm{p}$ line (see Fig. S1 of $\mathrm{ESI}^{\dagger}$ ). Although the growth of $\mathrm{Cr}$ is not two-dimensional, Cr thickness was estimated through a model of signal damping in a thin continuous film 40 using effective attenuation lengths (supplementary information of Ref.
25), bulk density and stoichiometry of $\mathrm{Cr}$ or $\mathrm{Cr}_{2} \mathrm{O}_{3}$. Low-energy electron diffraction (LEED) patterns of chromium deposits on alumina suffer from charge effects and from the lack of any diffraction spots. Those effects are likely related to the growth of a non-epitaxial layer and/or to nanoparticles 25 . To circumvent the problem, the crystallography of the $\mathrm{Cr}$ /alumina film was analyzed by reflection high energy electron diffraction (RHEED).

X-ray Absorption Spectroscopy (XAS) measurements were performed on the LUCIA beamline at synchrotron SOLEIL (France) in a UHV apparatus that involves the preparation and main chambers $\left(2.10^{-10} \mathrm{mbar}\right) \underline{41}$. Near-edge (XANES) and extended (EXAFS) spectra were collected at the $\mathrm{Cr} \mathrm{K}$ edge (around $6000 \mathrm{eV}$ ) in total electron yield mode by using a $\mathrm{Si}(111)$ monochromator. XAS spectra for the pure $\mathrm{Cr}$ metal and $\mathrm{Cr}_{2} \mathrm{O}_{3}$ oxide were collected as reference compounds. Data analyses were done using ATHENA and ARTEMIS packages 42 . Due to diffraction peaks from the alumina substrate, the extent of the EXAFS data is limited to $8 \AA^{-1}$ while the R-domain spans from 0.5 to $3 \AA$. Phase functions were extracted from FEFF9 calculations ${ }^{43}$ on $\mathrm{Cr}_{2} \mathrm{O}_{3}$ (Cr-O pairs), Cr metal (Cr-Cr pairs) and the intermetallic compound $\mathrm{Cr}_{5} \mathrm{Al}_{8}$ for $\mathrm{Cr}-\mathrm{Al}$ pairs.

Once introduced in vacuum in either apparatus, one-side epipolished $(9 \times 9 \times 0.5) \mathrm{mm}^{3} \alpha-\mathrm{Al}_{2} \mathrm{O}_{3}$ (0001) single crystals (supplier MaTeck ${ }^{44}$ ) were annealed at $\sim 1200-1500 \mathrm{~K}$ by electron bombardment of the holder under oxygen provided by a doser put at a millimetre distance of the surface to increase by more than one order of magnitude the local oxygen pressure ${ }^{45}$ (stationary pressure $2.10^{-6}$ mbar $)$. Such a preparation led to a sharp $(1 \times 1)$ LEED pattern. Contaminants, in particular carbon, were below the detection limit of XPS, except for calcium which segregates from bulk up to a maximum apparent coverage of $1 \AA$. Since such segregated Ca does not impact the long-range surface crystalline structure of alumina 46 , 48 , is absent from the local environment of Cr probed by XAS 24 and does not evolve upon Cr deposition (i.e. the Ca $2 \mathrm{p}$ level is unaffected), its presence was assumed not to affect the chemical state of $\mathrm{Cr}$. Cr was evaporated on substrates at room temperature from a metallic rod heated by electron bombardment (Omicron EFM3) whose flux was calibrated by a quartz microbalance (rate $\sim 1 \AA$ A. $s^{-1}$ ). However, thicknesses used herein refer only to XPS and XAS determination. This latter is achieved through a comparison of absorption threshold jumps. Although no significant metallic $\mathrm{Cr}$ ageing was observed over the time scale of measurements in either set-up, new substrates were systematically used for each deposit. As a reference, a $\mathrm{Cr}$ oxide film (thickness 16.2 ̊), hereafter labelled reference Cr oxide, was obtained by a prolonged oxidation at $T \sim 1575 \mathrm{~K}$ of a thick $\mathrm{Cr}$ film under gas doser ( $p=2 \cdot 10^{-6}$ mbar).

\subsection{Computational details}

All calculations were performed within the framework of the density functional theory (DFT) using the plane wave projector augmented-wave 49 (PAW) method implemented in the Vienna Ab-initio Simulation Package (VASP) 50 .53. Exchange-correlation 
effects were treated with dispersion-corrected optB88-vdW functional $54 / 55$. Moreover, $\mathrm{DFT}+\mathrm{U}$ approach proposed by Dudarev $\sqrt[567]{57}$ was applied to all configurations which involved $\mathrm{Cr}$ ions $\left(U_{C r}=3 \mathrm{eV}\right)$. Indeed, a solely vdW-DFT estimation may lead to an non-negligible (about $1 \mathrm{eV}$ ) underestimation of $\mathrm{Cr} 2 \mathrm{p}$ core level shifts (CLS) in configurations where $\mathrm{Cr}$ is ionized. The basis set included plane waves up to a kinetic energy of $400 \mathrm{eV}$.

As to describe $\mathrm{Cr}$ adatoms in a variety of realistic environments, alumina surface with $\mathrm{Cr}+\mathrm{O}_{3}, \mathrm{Cr}+\mathrm{O}_{2}, \mathrm{Cr}+\mathrm{O}_{2} \mathrm{H}$, and $\mathrm{Cr}+\mathrm{O}$ adspecies, which have been identified as thermodynamically stable under $\mathrm{H}$-lean conditions ${ }^{24}$ have been considered. These configurations involve $\mathrm{Cr}$ in $+6,+4,+3$, and +2 formal oxidation states, respectively. As a reference, an isolated $\mathrm{Cr}$ adatom on the alumina surface was also considered. All these configurations were modelled with a single $\mathrm{Cr}$ adatom [per $(1 \times 1)$ unit cell] adsorbed in the favoured hollow site of the Al-terminated $\mathrm{Al}_{2} \mathrm{O}_{3}(0001)$ surface 24 . The alumina substrate was represented by a slab composed of seven $\mathrm{Al}_{2} \mathrm{O}_{3}$ layers at the experimental in-plane bulk lattice parameter of $4.785 \AA$. The adspecies were adsorbed symmetrically on both slab surfaces and the coordinates of all atoms were relaxed until forces got lower than $0.01 \mathrm{eVA}^{-1}$. Furthermore, as to make a direct link to metallic $\mathrm{Cr}$ in bulk chromium and to $\mathrm{Cr}$ cations in bulk chromia, the same alumina slabs were sandwiched with five monolayer thick slabs of either metallic chromium or $\mathrm{Cr}_{2} \mathrm{O}_{3}$. In these superstructure calculations also the length of lattice vector perpendicular to the interfaces was optimized. Finally, reference bare Al-terminated and $\mathrm{OH}$-covered $\mathrm{Al}_{2} \mathrm{O}_{3}(0001)$ surfaces were also considered for CLS calculations. In all the ground state calculations, the Brillouin zone of the $(1 \times 1)$ surface cell was sampled with a $\Gamma$-centered $(8 \times 8)$ Monkhorst-Pack mesh.

The CLSs were further calculated in the complete screening approach 58 59, which includes the response of the valence electrons to the creation of a core hole. Screening by the other core-electrons was not taken into account, as it is generally environment-independent and therefore does not significantly influence the CLS 58 . The ground state configurations in a $(3 \times 3)$ surface unit cell were used as to minimize the interaction between the excited ions. Restricting the Brillouin-zone sampling to the $\Gamma$ point turned out to be sufficient.

\section{Chemistry and structure of $\mathrm{Cr}$ /alumina}

\subsection{Cr chemical state evolution from photoemission and XAS}

Fig. 1 - displays a series of $\mathrm{Cr} 2 \mathrm{p}$ spectra recorded for selected $\mathrm{Cr} / \alpha-\mathrm{Al}_{2} \mathrm{O}_{3}(0001)$ films, either metallic or purposely oxidized. The corresponding $\mathrm{Cr} 2 \mathrm{p}_{3 / 2}$ core level shift are given in Fig. 1 $\mathrm{b}$ as a function of the $\mathrm{Cr}$ thickness as well as that of the reference Cr oxide. They are compared to tabulated CLS related to $\mathrm{Cr}\left([\mathrm{Ar}] 3 \mathrm{~d}^{5} 4 \mathrm{~s}^{1}\right)$ formal oxidation states, from $\mathrm{Cr}^{0}$ to $\mathrm{Cr}^{6+}$, among which the most common and stable is $\mathrm{Cr}^{3+}$ (average values from database Ref. 37): $574.2 \pm 0.25 \mathrm{eV}\left(\mathrm{Cr}\right.$ metal, $\left.\mathrm{Cr}^{0}\right), 577.2 \pm 0.2 \mathrm{eV}$ $\left(\mathrm{Cr}(\mathrm{OH})_{3}, \mathrm{Cr}^{3+}\right), 576.6 \pm 0.6 \mathrm{eV}\left(\mathrm{Cr}_{2} \mathrm{O}_{3}, \mathrm{Cr}^{3+}\right), 575.85 \pm 0.6 \mathrm{eV}$
$\left(\mathrm{CrO}_{2}, \mathrm{Cr}^{4+}\right), \quad 579.3 \pm 0.6 \mathrm{eV}\left(\mathrm{CrO}_{3}, \mathrm{Cr}^{6+}\right) . \quad$ The tabulated apparent spin orbit splitting of the $\mathrm{Cr} 2 \mathrm{p}$ doublet is $9.25 \pm 0.08 \mathrm{eV}$ for $\mathrm{Cr}$ metal $\left(\mathrm{Cr}^{0}\right), 9.72 \pm 0.2 \mathrm{eV}$ for $\mathrm{Cr}_{2} \mathrm{O}_{3} \mathrm{eV}\left(\mathrm{Cr}^{3+}\right), 9.6 \pm 0.14 \mathrm{eV}$ for $\mathrm{CrO}_{2}\left(\mathrm{Cr}^{4+}\right)$.

Occurring in supported clusters 25 , the $\mathrm{Cr} 2 \mathrm{p}_{3 / 2}$ shifts could involve a final state screening of the positive photo-hole 60 ; estimate is given by $E_{F, m}=\alpha e^{2} / 4 \pi \varepsilon_{0} R$, where $R$ is the particle radius, $\varepsilon_{0}$ the vacuum permittivity and $\alpha$ a parameter around $0.5 \sqrt{61 \mid 62}$, so that the observed shift of $\sim 1 \mathrm{eV}$ could stem from clusters of around $1.5 \mathrm{~nm}$ in size. However, several arguments favour chemistry instead of electrostatics. Firstly, the $\mathrm{Cr} 2 \mathrm{p}$ line clearly exhibits a shoulder at higher binding energy, the overall contribution of which decays as the growth proceeds (Fig. 1.a). Other arguments come from XAS analysis. Fig. 2 compares Cr K-edge XAS spectra and modulus of corresponding Fourier transforms (FT) of various deposits and substrates: (a) $1.0 \AA$ thick $\mathrm{Cr}$ film and bulk $\mathrm{Cr}_{2} \mathrm{O}_{3}$; (b) 1.5 and $2.5 \AA$ thick $\mathrm{Cr}$ films; (c) $15 \AA$ thick Cr film and bulk Cr metal. Very similar contributions attributed to oxidized $\mathrm{Cr}$ are observed, in both edge and FT modulus, on the $1.0 \AA, 1.5 \AA$ and $2.5 \AA$ thick films (Fig. 2,a,b), which were shown to match distances and environments found in $\mathrm{Cr}-\mathrm{O}_{2} \mathrm{H}$ moieties 24 . The $15 \AA$ thick Cr film 24 compares to bulk metal (Fig. 2.c) although a small contribution is observed for similar $\mathrm{Cr}-\mathrm{O}$ distances observed with thinner coverages. Therefore, XAS demonstrates the occurrence of a defined interfacial oxidized environment in all $\mathrm{Cr}$ films.

To clarify the change of Cr chemistry and environment, the Cr $2 p$ line shape evolution was quantitatively analysed by focussing firstly on reference spectra of $\mathrm{Cr}$ metal and oxide (Fig. 3). Fits 64 were performed with Doniach-Sunjic 65 and Voigt profiles accounting for the X-ray source satellites $\frac{66}{6}$ with a fixed $1 / 2$ theoretical branching ratio of the $2 p$ lines and for an active Tougaard background 38 . The Lorentzian broadening was fixed at the $\mathrm{X}$-ray source width $(0.58 \mathrm{eV}$ for $\mathrm{Al}-\mathrm{K} \alpha$ and 0.54 for $\mathrm{Mg}-\mathrm{K} \alpha$ ) while the variable Gaussian width described instrumental resolution and distribution of chemical environments. The Cr 2p line shape recorded on the $17.7 \AA$ thick metallic film involves a Doniach-Sunjic profile (asymmetry $\alpha=0.35$ ) and a plasmon shifted by $24 \mathrm{eV} \underline{67}$; the interface contribution in this case remains negligible. The $\mathrm{Cr} 2 \mathrm{p}$ profile of the reference $\mathrm{Cr}$ oxide was fitted with a main line and a shake-up satellite shifted by $11.8 \mathrm{eV}$ (Fig. 3.b), as in the case of $\mathrm{Cr}_{2} \mathrm{O}_{3}$ 68.73; the complex multiplet splitting of the main line $68+76$ is accounted for in an effective way by an asymmetric line shape. Spin-orbit splitting (9.2 for the metal and $9.8 \mathrm{eV}$ for the oxide) and asymmetric line shapes match with expectations of $\mathrm{Cr}^{0}$ and $\mathrm{Cr}^{3+37}$. Above all, the $E_{B}\left(\mathrm{Cr} 2 \mathrm{p}_{3 / 2}\right)$ of $574.0 \mathrm{eV}$ and $576.2 \pm 0.25 \mathrm{eV}$ recorded on the metal and oxide, respectively, fairly agrees with tabulated values $\left(574.2 \pm 0.25 \mathrm{eV}\right.$ for $\mathrm{Cr}$ metal and $576.6 \pm 0.6 \mathrm{eV}$ for $\mathrm{Cr}_{2} \mathrm{O}_{3}{ }^{37}$ ). These two measurements increase our confidence in the employed binding energy scale calibration. In the XPS analysis of Cr/alumina, the overlap between O KLL and Cr LMM Auger transitions prevents the determination of Cr chemistry via Auger parameter, which led to use the tabulated $\mathrm{Al} 2 \mathrm{~s}$ peak position 

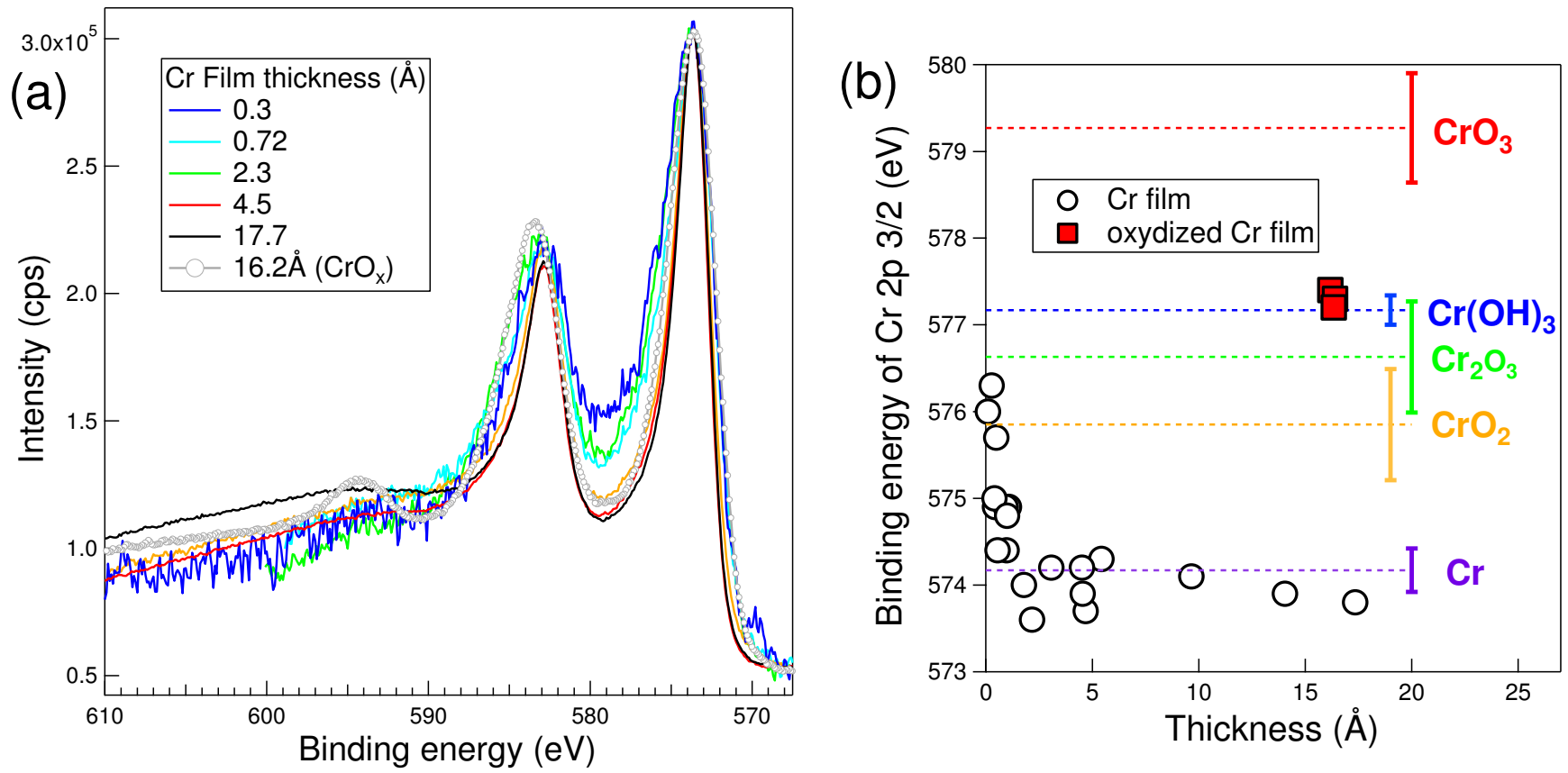

Fig. $1 \mathrm{Cr} 2 \mathrm{p}$ core levels from $\mathrm{Cr} / \mathrm{Al}_{2} \mathrm{O}_{3}(0001)$ films: (a) photoemission spectra aligned on background and peak maximum to highlight line shape changes. Bare surface spectra have been subtracted after suitable intensity normalization to remove the double plasmon excitation of $\mathrm{O} 1 \mathrm{~s}$ below $\mathrm{Cr} 2 \mathrm{p}_{1 / 2}$. A comparison is made with a thick purposely oxidized $\mathrm{Cr}$ film $\left(\mathrm{CrO}_{x}\right)$. Charge effects have been corrected by using Al $2 \mathrm{~s}$ binding energy as an internal reference. (b) Evolution of the $\mathrm{Cr} 2 \mathrm{p}_{3 / 2}$ binding energy with $\mathrm{Cr}$ thickness (circles). Squares correspond to the oxidized $\mathrm{Cr}$ film. For comparison, average (horizontal lines) and range (error bars) of tabulated values are given for various $\mathrm{Cr}$ oxidation states on corresponding bulk (hydr)oxides 37 (see text).

$\left(E_{B}=119.6 \mathrm{eV}^{37}\right)$ as a reference to overcome charge effects. Constant $\mathrm{Al} 2 \mathrm{~s}$ profile (see below) and $E_{B}(\mathrm{O} 1 \mathrm{~s})=531.5 \pm 0.1 \mathrm{eV}$ value justify the approach.

Even at very low $\mathrm{Cr}$ /alumina coverage, visual inspection of $\mathrm{Cr} 2 \mathrm{p}_{3 / 2}$ profiles (Fig. 1 a) and fits indicate that $\mathrm{Cr}$ films involve both metal and oxide. To enhance the relative contribution of the oxide, an example of $\mathrm{Cr}$ /alumina film was taken in the submonolayer Cr coverage range $(0.34 \AA)$; the corresponding $\mathrm{Cr} 2 \mathrm{p}, \mathrm{O} 1 \mathrm{~s}$ and $\mathrm{Al} 2 \mathrm{~s}$ core levels are shown in Fig. 4. After substraction of the second order of the $\mathrm{O} 1 \mathrm{~s}$ plasmon satellite at low thicknesses (Fig. S1 of $\mathrm{ESI}^{\dagger}$ ), the $\mathrm{Cr} 2 \mathrm{p}$ profile was decomposed into two components corresponding to metallic and oxidized Cr (Fig.4.a). The above defined line shape (Fig. 3 a) and energy position $\left(E_{B}\left(\mathrm{Cr} 2 \mathrm{p}_{3 / 2}\right)=574.0 \mathrm{eV}\right)$ were used to represent the metallic contribution of the Cr 2p spectra. A spin-orbit splitting of $9.7 \mathrm{eV}$ and a Cr $2 \mathrm{p}$ CLS of $+2.5 \mathrm{eV}$ were found to accurately represent the oxide component. However, the complex multiplet splitting and shake-up satellite were ignored. Such a pragmatic fitting approach 69:70|72/73 yielded to an oxidized component broader $\left(\mathrm{FWHM}_{G} \simeq 5.2 \mathrm{eV}\right)$ than the metallic one $\left(\mathrm{FWHM}_{G} \simeq 2.2 \mathrm{eV}\right)$. The equivalent thickness of oxidized metal was estimated to $0.07 \pm 0.02 \AA$ in the (110) body-centred stacking of Cr with a lattice parameter of $2.91 \AA$. Assuming a $\mathrm{Cr}+\mathrm{O}_{2} \mathrm{H}$ adsorption configuration 24 , such an amount corresponds to a reaction with $1.1 \pm 0.3 \mathrm{OH} . \mathrm{nm}^{-2}$. At higher $\mathrm{Cr}$ coverage, Cr $2 \mathrm{p}$ spectra can be fitted in a similar way (Fig. S2 of $\mathrm{ESI}^{\dagger}$ ) but, because of the decrease in the relative weight of the component which corresponds to the oxide, the quantitative analysis becomes less reliable. However, a key point is that the oxide contribution keeps a constant profile and decreases in relative intensity (Fig. S2 of $\mathrm{ESI}^{\dagger}$ ), which supports the XAS view of the absence of formation of intermediate oxidation states at the $\mathrm{Cr} / \mathrm{Cr}-\mathrm{O}_{2} \mathrm{H}$ interface.

\subsection{Crystallinity of metallic Cr/alumina films}

The status of metallic $\mathrm{Cr}$ remains unclear since metallic environment with $\mathrm{Cr}-\mathrm{Cr}$ distances of 2.50 and $2.91 \AA$ characteristic of body-centred cubic structure is only observed in thicker $\mathrm{Cr}$ films (here $15 \AA$ ), although the previously obtained number of $\mathrm{Cr}$ neighbours does not match that found in bulk metal 24. In Table 1 of Ref. 24, the fitting procedure set-up was kept identical to that used for thin films. This led to abnormally low coordination numbers for the thick $\mathrm{Cr}$ film. For a more precise description of this thick film, the initial parameters were allowed to go towards those of $\mathrm{Cr}$ metal. This did not change the oxygen coordination, but increased the $\mathrm{Cr}-\mathrm{Cr}$ coordination numbers and the disorder parameters to values in line with an ill-crystallized metallic layer built on top of a first layer of $\mathrm{Cr}-\mathrm{O}$ moieties, analogous to those found in the very thin film. In agreement, the near edge structure of the $15 \AA \mathrm{Cr}$ film is closer to bulk Cr metal than to $\mathrm{Cr}$ oxide (Fig. 2.c). In particular the pre-edge at $5995 \mathrm{eV}$ is characteristic of 3d-metals. The decrease in intensity of the main FT peak at $1.35 \AA$ (associated to $\mathrm{Cr}-\mathrm{O}$ ) as the Cr thickness increases (Fig. 2-a,b) can be related to a growing proportion of $\mathrm{Cr}$ atoms not directly linked to oxygen. Nevertheless the 

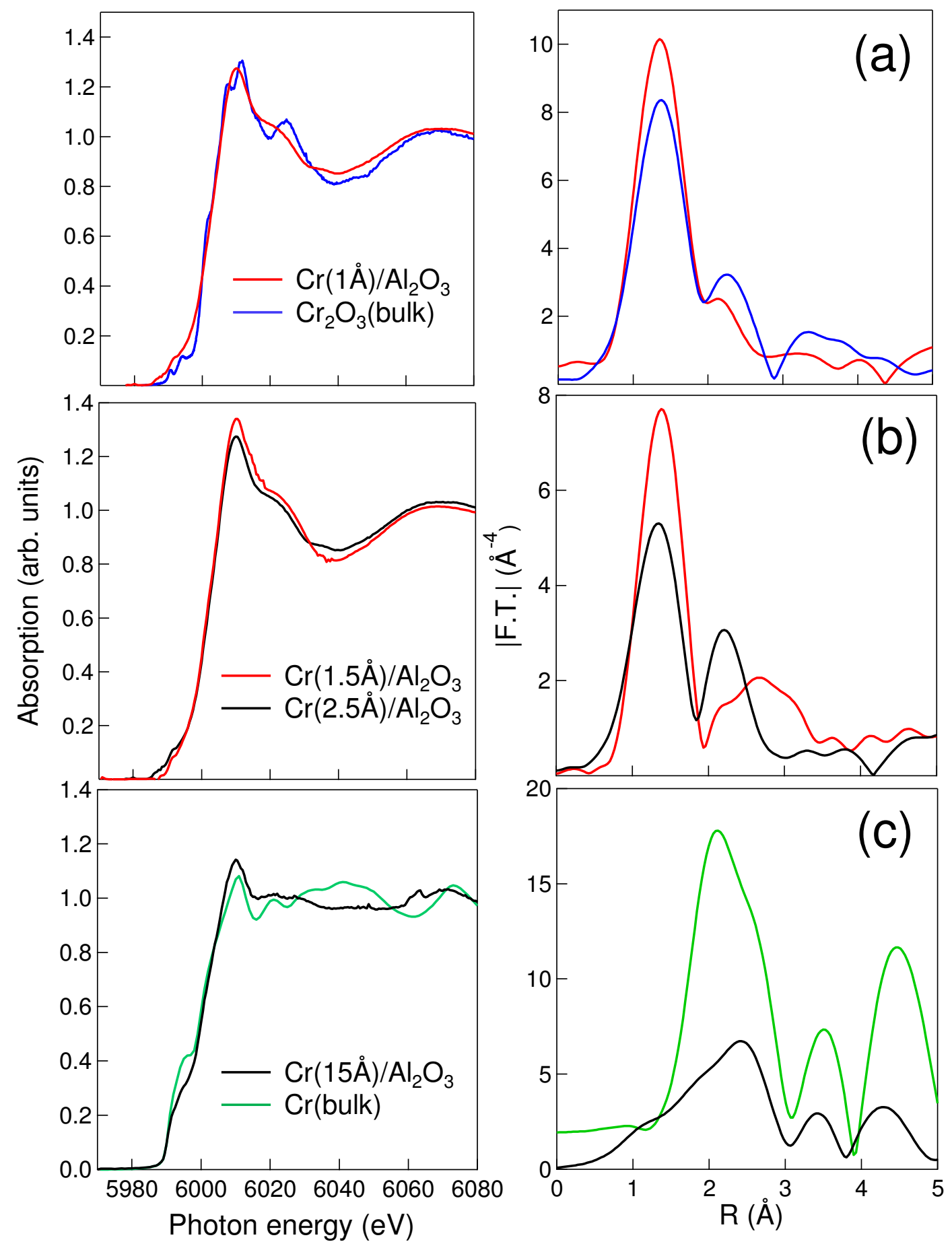

Fig. 2 XAS spectra (left) and modulus of the extended $\mathrm{x}$-ray absorption fine structure (EXAFS) Fourier transform (right) at the $\mathrm{Cr} \mathrm{K}$ edge for the following samples: (a) $1.0 \AA$ thick $\mathrm{Cr}$ /alumina film (red) and bulk $\mathrm{Cr}_{2} \mathrm{O}_{3}$ (blue); (b) 1.5 (red) and $2.5 \AA$ (black) thick Cr/alumina films; (c) $15 \AA$ thick $\mathrm{Cr}$ /alumina film (black) and bulk $\mathrm{Cr}$ metal (green). 

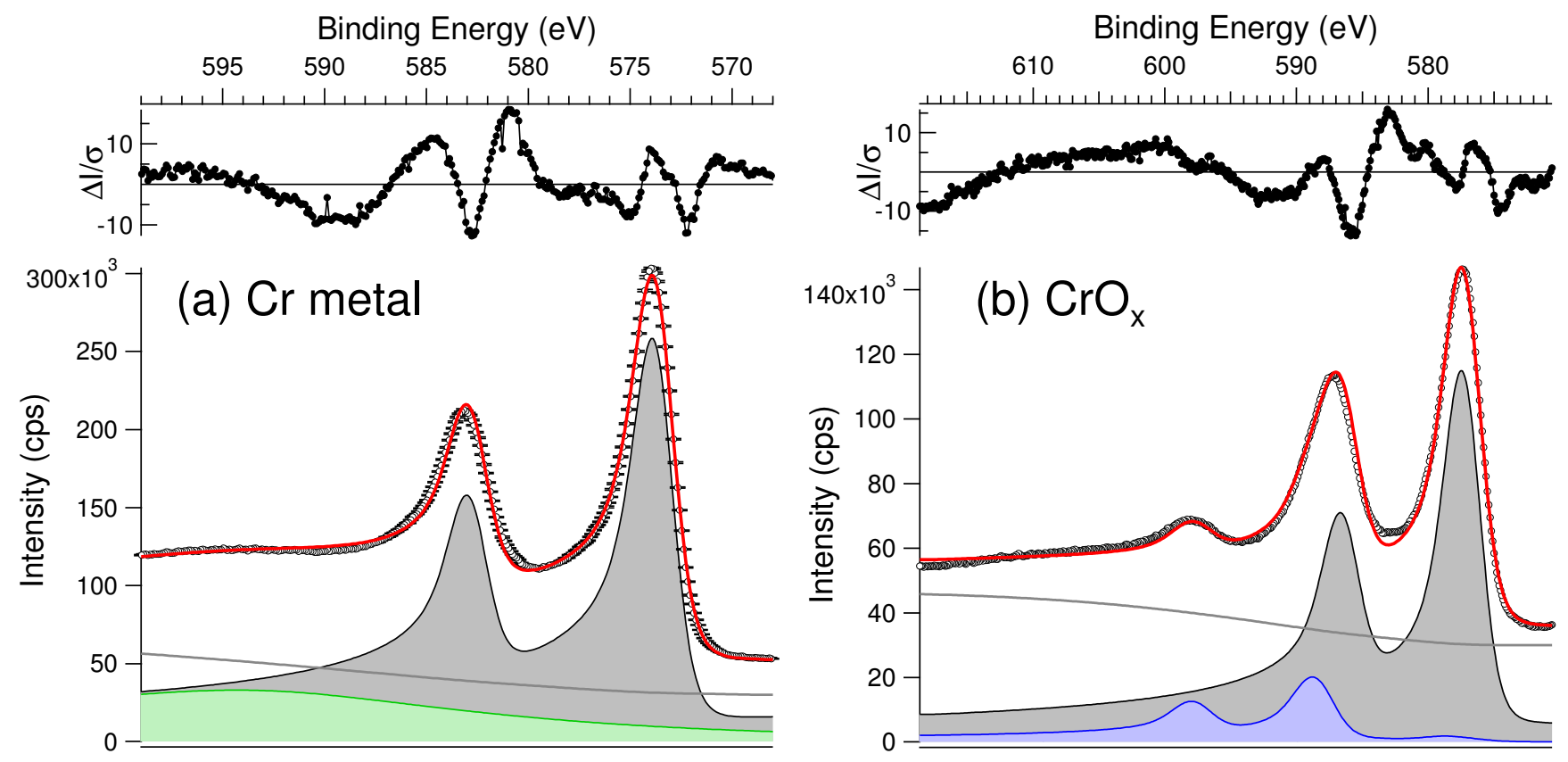

Fig. 3 Fit (red line) of the $\mathrm{Cr} 2 \mathrm{p}$ core level (black points) in $\mathrm{Cr}$ /alumina films (see text): (a) $17.7 \AA$ thick $\mathrm{Cr}$ film; the metallic component (grey) of Doniach-Sunjic line shape is accompanied by a broad plasmon (green); (b) purposely oxidized $16.2 \AA$ thick $\mathrm{Cr}$ film; both the main line shape (grey) and the shake-up satellite (blue) are featured. In both figures, the grey lines correspond to the Tougaard background and the top line to residuals normalized by error taken as the square-root of the intensity.
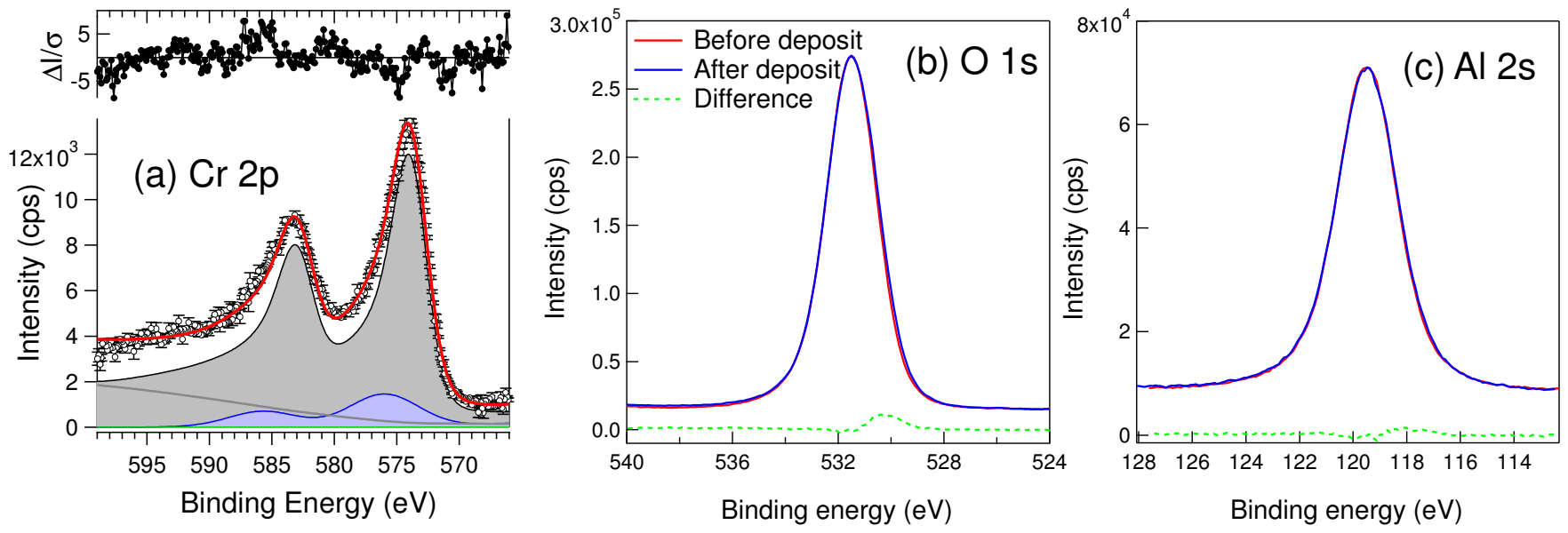

Fig. 4 Core level profiles of a $\operatorname{Cr}(0.34 \AA)$ /alumina deposit: (a) Fit (red line) of the $\mathrm{Cr} 2 \mathrm{p}$ core level (black points) with metallic (grey curve) and oxidized (blue curve) components (see text for explanations), (b) O 1s and (c) Al $2 \mathrm{~s}$. The difference curve before and after deposition is shown as a dotted line in Figs.-b,c. 
near edge structure of intermediate thicknesses remains very similar to that of the thinner deposit, without combined $\mathrm{Cr}-\mathrm{Cr}$ distances around 2.5 and $2.90 \AA$, which are the signature of metallic Cr. The second FT peak is difficult to model properly in these films, but it is made of an increasing number of disordered $\mathrm{Cr}-\mathrm{Cr}$ distances between 2.5 and $2.9 \AA$ A. The link between the two structures could be the $\mathrm{Cr}$ - $\mathrm{Cr}$ distance at $2.9 \AA$ which is common to $\mathrm{Cr}_{2} \mathrm{O}_{3}$ and $\mathrm{Cr}$ metal.

The poor crystallinity of the $\mathrm{Cr}$ film, which perturbs the fitting process of the EXAFS data, is supported by RHEED analysis. Fig. 55a shows a set of diffraction patterns recorded at different $\mathrm{Cr}$ thicknesses for an electron beam aligned along the [100] direction of $\mathrm{Al}_{2} \mathrm{O}_{3}(0001)$. As seen directly from the pattern (Fig. 5-a), the intensity profiles (Fig. 5-b) or the integrated intensity compared to background (Fig. 5. c), diffraction rods of the alumina surface rapidly vanish to reach a nearly uniform background level beyond a Cr thickness of about $5 \AA$ A. Only for thick Cr films, a low contrast ring shape typical for a poorly crystallized or amorphous layer is recovered (pink line in Fig.55a). This ring is isotropic as it is independent of the sample azimuth. The comparison of its radius to the reference on the bare alumina gives a distance of $d=2.57 \pm 0.05 \AA$ in line with metallic Cr. This lack of crystallinity of the $\mathrm{Cr}$ films, as seen by RHEED, agrees with the absence of definite local order for $\mathrm{Cr}$ not linked to oxygen which is inferred from XAS analysis.

\section{Core level shifts determined by $a b$ initio calculations to understand the $\mathrm{Cr}$ /alumina interface}

Chemicals shifts of all elements involved in the $\mathrm{Cr}$ /alumina system are now analysed as a whole. In parallel to $\mathrm{Cr}$ deposition, slight changes in $\mathrm{O}$ 1s (Fig. 4 b) and $\mathrm{Al} \mathrm{2s} \mathrm{(Fig.} \mathrm{4} \mathrm{c}$ ) profiles are observed, with contributions shifted by $-1.3 \pm 0.3 \mathrm{eV}(\mathrm{O} 1 \mathrm{~s})$ and $\sim-1.1$ to $-2 \mathrm{eV}(\mathrm{Al} 2 \mathrm{~s})$. These are now compared to calculated counterparts (Fig. 6). Numerical simulations representing all degrees of $\mathrm{Cr}$ oxidation have been performed by a DFT $+\mathrm{U}$ approach $(U=3 \mathrm{eV})$ on purposely designed configurations $\mathrm{CrO}_{x}$ (Table 1) corresponding to a Cr coverage of the order of a monolayer, as in experiments, since comparison with values recorded on bulk compounds (Fig. 1 b) are not fully relevant in such a context. Selected structures involve $\mathrm{Cr}^{6+}, \mathrm{Cr}^{4+}, \mathrm{Cr}^{3+}$, and $\mathrm{Cr}^{2+}$ oxidation states, which were shown to be thermodynamically the most stable among configurations formed upon reaction of $\mathrm{Cr}$ with surface $\mathrm{OH}$ groups on alumina ${ }^{24}$. The isolated $\mathrm{Cr}$ adatom $\left(\mathrm{Cr}^{0}\right), \mathrm{Cr}$ in the oxide $\mathrm{Cr}_{2} \mathrm{O}_{3}$ and in bulk $\mathrm{Cr}$ metal $(U=0 \mathrm{eV})$ have also been calculated, as well as bare and water-covered $\mathrm{Al}_{2} \mathrm{O}_{3}(0001)$ surfaces that are taken as references for $\mathrm{O} 1 \mathrm{~s}$ and $\mathrm{Al} 2 \mathrm{~s}$ core levels. All these atomic configurations are displayed on the periphery of Fig. 6

Fig. 6 is a guide for the discussion that follows, with appropriate color codes for the debated configurations, CLS and atoms. The present and tabulated ${ }^{37}$ absolute $E_{B}(\mathrm{Cr} 2 \mathrm{p})$ values related to $\mathrm{Cr}$ metal and $\mathrm{Cr}_{2} \mathrm{O}_{3}$, and the corresponding theoretical CLS nicely compare (Fig. 6-a,b). The value of the O 1s CLS associated to surface $\mathrm{OH}$ recorded at 1.4-1.5 $\mathrm{eV}$ from the bulk component (Fig. S3 of ESI ${ }^{\dagger}$ ), in agreement with the commonly found values of 1.3-1.6 eV 18/77-79 agrees in trend with the present theoretical estimate (2.3 eV, Fig. 6-b). Indeed, the calculated absence of $\mathrm{O} 1 \mathrm{~s}$ shift of terminal $\mathrm{O}$ atoms associated to the bare $\alpha-\mathrm{Al}_{2} \mathrm{O}_{3}(0001)$ (Fig. 6.b) discards the interpretation ${ }^{80}$ of the $1.3-1.6 \mathrm{eV}$ shift observed after annealing in vacuum as related to the bare surface and argues for the assignment of that shift to surface $\mathrm{OH}$. This point is important as $\mathrm{OH}$ groups strongly impact the wetting of alumina surface by metals 2224178179181 and, more speculatively, the dispersion of its isoelectric point ${ }^{82}$ and its structure ${ }^{83}$. Clearly, the poorly understood residual $\mathrm{OH}$ coverage is a key to the surface properties of the oxide. The correct agreement between measurements and calculations for those well-defined systems ( $\mathrm{Cr}$ metal and oxide, surface $\mathrm{OH}$ of alumina) proves the robustness of the calculations which include final state effects and validates the employed $U$ value.

The experimental value of $2.5 \mathrm{eV}$ for the $\mathrm{Cr} 2 \mathrm{p}$ shift associated to the oxidized $\mathrm{Cr}$ in $\mathrm{Cr}$ /alumina films is very discriminating. It reasonably agrees with CLS values calculated for $\mathrm{Cr}^{3+}\left(\mathrm{Cr}-\mathrm{O}_{2} \mathrm{H}\right)$ and $\mathrm{Cr}^{4+}$, but it much differs from what is expected for $\mathrm{Cr}^{6+}$, $\mathrm{Cr}^{2+}$ and $\mathrm{Cr}^{0}$ (Fig. 6-a). CLS related to $\mathrm{O} 1 \mathrm{~s}$ support the finding although they are less discriminating (Fig. 66). However, there is a clear gap between the $\mathrm{O}$ 1s shift associated to $\mathrm{Cr}_{2} \mathrm{O}_{3}$ and that related to the oxide component of the $\mathrm{Cr} /$ alumina (Fig. 66 b), which confirms that the latter species differs from the bulk oxide. In addition, the only calculated $\mathrm{Cr}-\mathrm{O}$ distances that match the XAS analysis are those found in the $\mathrm{Cr}-\mathrm{O}_{2} \mathrm{H}$ moieties ${ }^{24}$ (Table 17). The $\mathrm{Al} 2$ s profile changes upon $\mathrm{Cr}$ deposition, with a contribution shifted by $\sim-1.1$ to $-2 \mathrm{eV}$ with respect to the bulk component (Fig. 4 c). Such an $\mathrm{Al} 2 \mathrm{~s}$ shift is much smaller than that which is expected between the $\mathrm{Al}$ metal and $\mathrm{Al}_{2} \mathrm{O}_{3}(-2.7 \text { to }-3.3 \mathrm{eV})^{18 / 37}$. In agreement with the picture derived by optics 25 of metallic $\mathrm{Cr}$ clusters anchored by oxidized entities that cover progressively the surface and the limited fraction of oxidized $\mathrm{Cr}$ as shown by the $\mathrm{Cr} 2 \mathrm{p}$ profile (Fig. 1 and Fig. S2 of $\mathrm{ESI}^{\dagger}$ ), the experimental Al 2s CLS matches that characteristic of a contact between bulk $\mathrm{Cr}$ and alumina (Fig. 4 $4 \mathrm{c}$ ). Therefore, the reduction of the $\alpha-\mathrm{Al}_{2} \mathrm{O}_{3}(0001)$ substrate by $\mathrm{Cr}{ }^{33344}$ is ruled out, in agreement with the DFT approach ${ }^{24}$ and in a manner similar to Ti ${ }^{18184}$ or $\mathrm{Co}^{79}$, which confirms that the reaction with surface $\mathrm{OH}$ groups ${ }^{24}$ is the only route for $\mathrm{Cr}$ oxidation. However, contrary to what was observed for $\mathrm{Ti} / \mathrm{alumina}{ }^{18}$, no depletion due to the reaction of $\mathrm{Cr}$ with $\mathrm{OH}^{24}$ appears on the higher $\mathrm{O} 1 \mathrm{~s}$ binding energy side (Fig. 4 b). This leads to postulate a compensation of the depletion by inelastic energy losses undergone by photoelectrons on their way through the $\mathrm{Cr}$ metallic film, as evidenced at the Ti/alumina interface $\frac{18}{18}$. The argument is supported by the systematic presence of metallic $\mathrm{Cr}$ in $\mathrm{Cr} 2 \mathrm{p}$ core level even for the lowest deposited $\mathrm{Cr}$ amount (Fig.4 4 a).

Overall, the XPS analysis shows that, upon Cr deposition, the $\mathrm{Cr}$ film involves an oxidized $\mathrm{Cr}$ species in limited amount and 

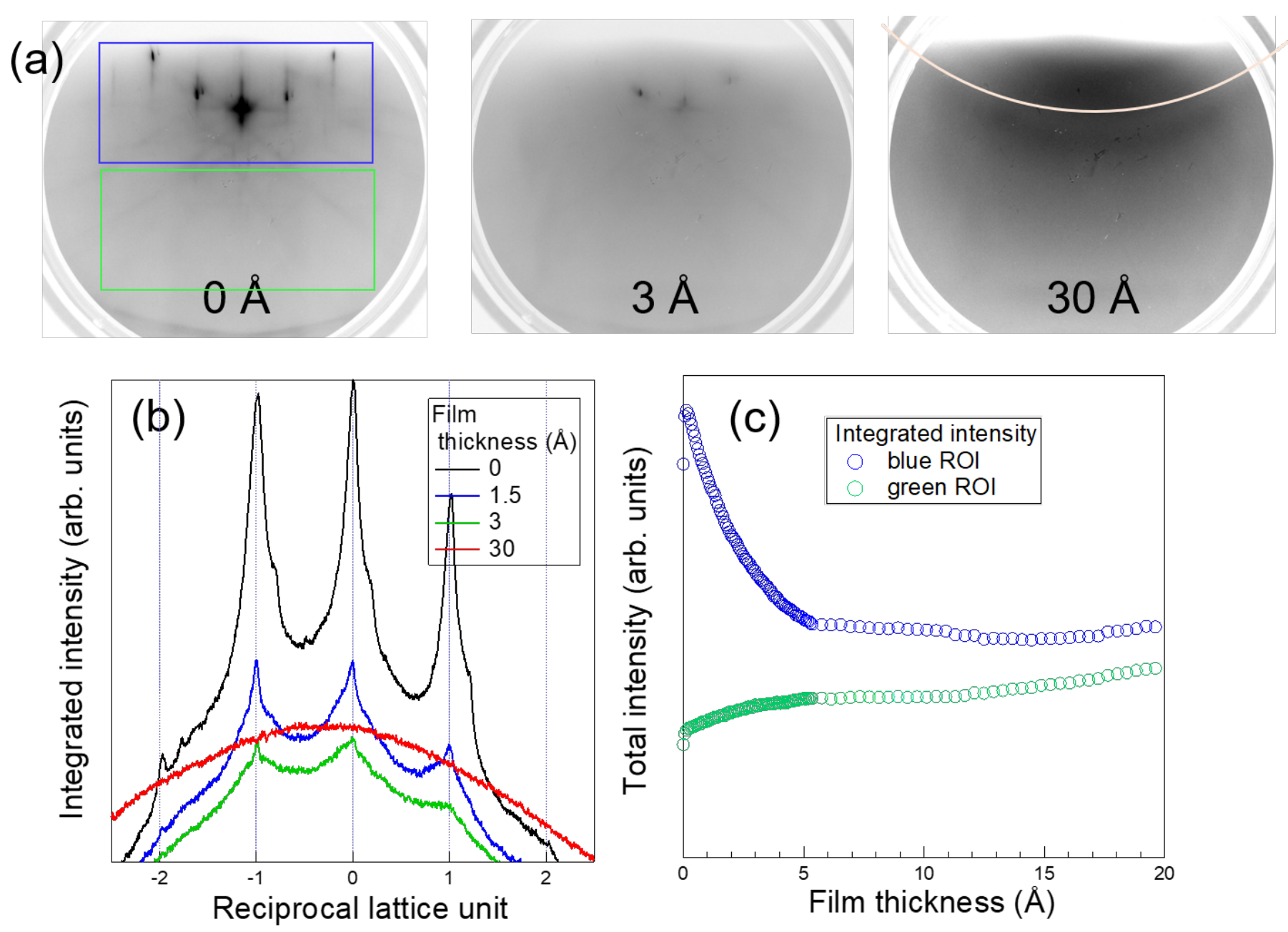

Fig. 5 (a) Evolution of the RHEED diffraction pattern (beam energy of $9.5 \mathrm{keV}$ ) along the [100] direction of $\mathrm{Al}_{2} \mathrm{O}_{3}(0001)$ upon $\mathrm{Cr}$ deposition. $\mathrm{Film}$ thickness calibrated by XPS is given on the figure. The pink line at the end of the deposit points to a polycrystalline layer; (b) Intensity cross section (integrated over the blue region of interest (ROI) of figure-a) as a function of alumina reciprocal space coordinate; (c) Integrated signal (blue ROI) and background (green ROI) of figure-a versus film thickness. The evaporation rate was $\sim 0.4 \AA / \mathrm{min}$. 


\begin{tabular}{lcccll} 
config. & $Q_{C r}$ & $\mu_{C r}$ & $\mathrm{Cr}^{z+}$ & $d(\mathrm{Cr}-\mathrm{O})$ & \multicolumn{1}{c}{ Conflicts of interest } \\
\hline \hline $\mathrm{Cr}+\mathrm{O}_{3}$ & +2.1 & 0.0 & 6 & $2.13,2.13,2.13 ; 1.66,1.66,1.66_{\text {There }}$ & are no conflicts to declare. \\
$\mathrm{Cr}+\mathrm{O}_{2}$ & +1.8 & 2.1 & 4 & $1.95,2.17,2.19 ; 1.70,1.71$ & \\
$\mathrm{Cr}+\mathrm{O}_{2} \mathrm{H}$ & +1.6 & 2.9 & 3 & $1.98,2.04,2.18 ; 1.79,1.89$ & Acknowledgements \\
$\mathrm{Cr}+\mathrm{O}$ & +1.3 & 3.9 & 2 & $2.09,2.33,2.38 ; 1.96$ & \\
$\mathrm{Cr}$ & +0.8 & 4.3 & 0 & $2.22,28,2.08$ &
\end{tabular}

$\begin{array}{lllll}\mathrm{Cr} & +0.8 & 4.3 & 0 & 2.32,2.28,2.08\end{array}$

$\mathrm{Cr}_{2} \mathrm{O}_{3}+1.7 \quad 2.8 \quad 3$

Cr (metal) $+0.0 \quad 0.4 \quad 0$

The team in charge of the SOLEIL machine is warmly acknowl-

Table 1 Calculated electronic and structural characteristics of $\mathrm{Cr}$ atoms in the different considered configurations: Bader charges $Q_{C r}(\mathrm{e})$, magnetic moments $\mu_{C r}\left(\mu_{B}\right)$, formal oxidation states $\mathrm{Cr}^{z+}$, and $\mathrm{Cr}-\mathrm{O}$ bond lengths $d(C r-O)(\AA)$. For adspecies, the first three bond lengths correspond to these with oxygen atoms in the $\mathrm{Al}_{2} \mathrm{O}_{3}$ substrate.

metallic $\mathrm{Cr}$ that coexist from the very beginning of the formation of the interface. Despite the limits of the present comparisons, in which theory approximates complex situations with model structures ${ }^{24}$, reasonable agreements are found. The oxide stems from the reaction of $\mathrm{Cr}$ with surface $\mathrm{OH}$, the reduction of the substrate by $\mathrm{Cr}$ being totally excluded. The $\mathrm{Cr} 2 \mathrm{p}, \mathrm{O} 1 \mathrm{~s}$ and Al 2s CLS observed upon $\mathrm{Cr}$ deposition are compatible with the formation of the previously identified $\mathrm{Cr}-\mathrm{O}_{2} \mathrm{H}$ moieties, although photoemission alone does not discriminate between $\mathrm{Cr}^{3+}$ and $\mathrm{Cr}^{4+}$ oxidation states. Metallic $\mathrm{Cr}$ clusters grow partly in contact with the alumina substrate, i.e independently of the $\mathrm{Cr}$ oxide, although $\mathrm{Cr}-\mathrm{O}$ distances characteristic of the $\mathrm{Cr} /$ alumina interface are not evidenced in XAS. Such a configuration is in full agreement with the model of seed layer which was previously derived from optical measurements 25 .

\section{Conclusion}

Chemical states of all the elements involved in the $\mathrm{Cr} / \alpha$ $\mathrm{Al}_{2} \mathrm{O}_{3}(0001)$ interface have been analysed by photoemission and $\mathrm{x}$-ray absorption spectroscopy combined with the determination of chemical shifts by density functional approach involving final state effects. This scarcely-employed combination of spectroscopic measurements and calculations demonstrates that, at the onset of its deposition, $\mathrm{Cr}$ is oxidized by reaction with the surface $\mathrm{OH}$ groups to mainly form $\mathrm{Cr}^{3+}$ in the form of $\mathrm{Cr}+\mathrm{O}_{2} \mathrm{H}$ moieties, in agreement with previous findings ${ }^{24}$, although the formation of $\mathrm{Cr}^{4+}$ is not excluded. $\mathrm{Cr}$ does not reduced the alumina substrate. Most importantly, some $\mathrm{Cr}$ is initially deposited in metallic form, in parallel to oxidized species, but the formation of intermediate oxidation states at the $\mathrm{Cr} / \mathrm{Cr}-\mathrm{O}_{2} \mathrm{H}$ interface is excluded, which fully supports the previously described $\mathrm{Cr}$ /alumina buffer mechanism 25 . A difficulty in analysing the $(\mathrm{Cr}+\mathrm{Cr}$ oxide)/alumina interface arises from the poorly ordered character of $\mathrm{Cr}$, at long and even at short distances, up to large thicknesses. This situation is likely caused by the presence of oxidized $\mathrm{Cr}$ at the interface although the well-known low-diffusivity of $\mathrm{Cr}$ may also impact the ordering ${ }^{25}$. The study of chemical states (photoemission and near-edge spectroscopy) then become a pivotal approach of the system. 

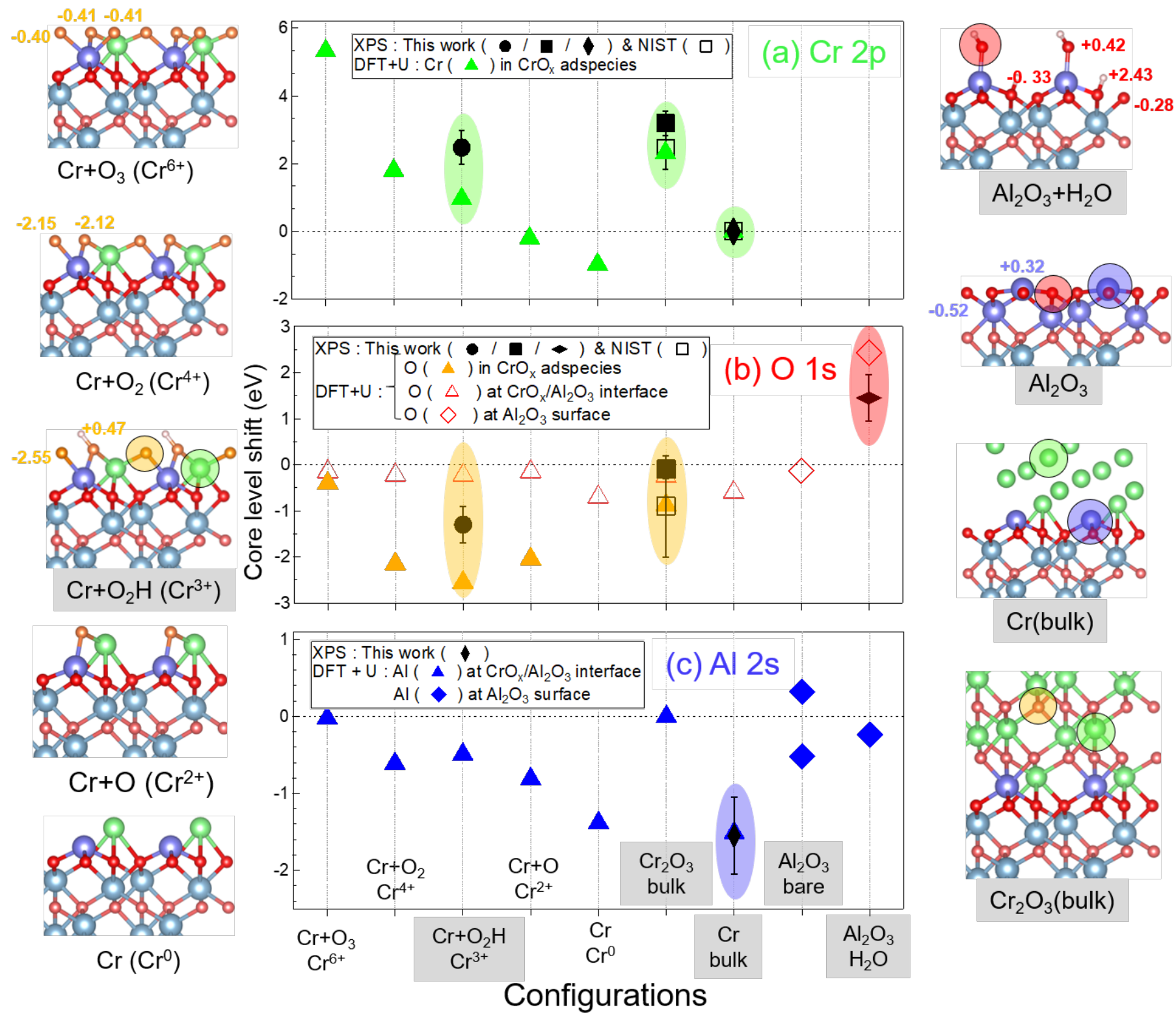

Fig. 6 Comparison between experimental (this work : black filled symbols; NIST references : black opened squares) and calculated (triangles and diamonds) core level shifts: (a) $\mathrm{Cr} 2 \mathrm{p}$, (b) $\mathrm{O} 1 \mathrm{~s}$ and (c) Al 2s. Calculations are done by DFT $+\mathrm{U}\left(U_{C r}=3 \mathrm{eV}\right)$ for the configurations which are represented as ball models on each side of the figure (bulk Al: light blue; $\mathrm{Al}_{2} \mathrm{O}_{3}$ surface Al: blue; bulk $\mathrm{O}$ : light red; $\mathrm{Al}_{2} \mathrm{O}_{3}$ surface $\mathrm{O}$ : red; $\mathrm{O}$ in $\mathrm{Cr}+\mathrm{O}_{x}$ adspecies: orange; $\mathrm{H}$ : white). Adsorbed $\mathrm{Cr}$ /alumina configurations with their formal oxidation states appear on the left hand side: $\mathrm{Cr}^{6+}\left(\mathrm{Cr}_{+} \mathrm{O}_{3}\right)$, $\mathrm{Cr}^{4+}\left(\mathrm{Cr}+\mathrm{O}_{2}\right), \mathrm{Cr}^{3+}\left(\mathrm{Cr}+\mathrm{O}_{2} \mathrm{H}\right.$, Ref. 24) $\mathrm{Cr}^{2+}(\mathrm{Cr}+\mathrm{O}), \mathrm{Cr}^{0}(\mathrm{Cr})$. Atomic configurations related to bulk compounds $\left(\mathrm{Cr}^{3+}\left(\mathrm{Cr}_{2} \mathrm{O}_{3}\right)\right.$ and $\mathrm{Cr}$ bulk metal) and alumina surface (bare $\mathrm{Al}_{2} \mathrm{O}_{3}$ and hydroxylated $\mathrm{Al}_{2} \mathrm{O}_{3}+\mathrm{H}_{2} \mathrm{O}$ ) appear on the right hand side. Theoretical $\mathrm{CLSs}$ are referenced to atoms in the center of the bulk $\mathrm{Cr}$ slab (Fig. a, $\mathrm{Cr} 2 \mathrm{p}$, green triangles) and to atoms in the center of the $\mathrm{Al}_{2} \mathrm{O}_{3}$ slab (Fig. b, O 1s, yellow triangles; $\mathrm{Al} 2 \mathrm{~s}$, Fig. $\mathrm{c}$, blue triangles). $\mathrm{O} 1 \mathrm{~s} \mathrm{CLS}$ at the $\mathrm{Cr}+\mathrm{O}_{x} / \mathrm{Al}_{2} \mathrm{O}_{3}$ are shown in Fig. b as red empty triangles. Similar convention was adopted for $\mathrm{Al}_{2} \mathrm{O}_{3}$ and $\mathrm{Al}_{2} \mathrm{O}_{3}+\mathrm{H}_{2} \mathrm{O}$ (Fig. b: red empty diamonds; Fig. c: blue filled diamonds). Extra-values of CLSs are given on an atom-by-atom basis in the ball models. The configurations whose calculated chemical shifts are compared to the experiment are highlighted by shaded grey areas. In Fig. a, b and c, comparisons are indicated by light green $(\mathrm{Cr} 2 \mathrm{p})$, yellow $\left(\mathrm{O} 1 \mathrm{~s}\right.$ in $\left.\mathrm{Cr}+\mathrm{O}_{x}\right)$, red $\left(\mathrm{O} 1 \mathrm{~s}\right.$ at $\mathrm{Cr}+\mathrm{O}_{x} / \mathrm{Al}_{2} \mathrm{O}_{3}$ interfaces) and blue (Al $\left.2 \mathrm{~s}\right)$ areas. In configurations drawn on each side of the figure, corresponding atoms are indicated by circles of the same colors. 


\section{Notes and references}

1 K. Fukuda, S. H. M. Lim and A. Anders, Thin Solid Films, 2008, 516, 4546-4552.

2 H. Aouani, J. Wenger, D. Gérard, H. Rigneault, E. Devaux, T. W. Ebbesen, F. Mahdavi, T. Xu and S. Blair, ACS Nano, 2009, 3, 2043-2048.

3 V. J. Logeeswaran, N. P. Kobayashi, M. S. Islam, W. Wu, P. Chaturvedi, N. X. Fang, S. Y. Wang and R. S. Williams, Nano Letters, 2009, 9, 178-182.

4 T. Siegfried, Y. Ekinci, O. J. F. Martin and H. Sigg, ACS Nano, 2013, 7, 2751-2757.

5 M. Todeschini, A. Bastos da Silva Fanta, F. Jensen, J. B. Wagner and A. Han, ACS Applied Material \& Interfaces, 2017, 9, 37374-37385.

6 N. Formica, D. S. Ghosh, A. Carrilero, T. L. Chen, R. E. Simpson and V. Pruneri, ACS Applied Materials \& Interfaces, 2013, 5, 3048-3053.

7 R. Henriquez, R. Roco, S. Bravo, V. Del Campo, C. GonzalezFuentes, S. Donoso and P. Häberle, Appl. Surf. Sci., 2019, 489, 403-408.

8 G. Dehm, C. Scheu, M. Rühle and R. Raj, Acta. Mater., 1998, 46, 759-771.

9 M. Sterrer and H. J. Freund, Catal. Lett., 2013, 143, 375-385.

10 S. L. Hemmingson and C. T. Campbell, ACS Nano, 2017, 11, 1196-1203.

11 C. T. Campbell, S. C. Parker and D. E. Starr, Science, 2002, 298, 811.

12 Q. Fu and T. Wagner, Surf. Sci. Rep., 2007, 62, 431-498.

13 A. G. Evans, J. W. Hutchinson and Y. Wei, Acta Mater., 1999, 47, 4093-4113.

14 C. V. Thompson, Annu. Rev. Mater. Res., 2012, 42, 399-434.

15 P. Jacquet, R. Podor, J. Ravaux, J. Teisseire, I. Gozhyk, J. Jupille and R. Lazzari, Scr. Mater., 2016, 115, 128 - 132.

16 P. Jacquet, R. Podor, J. Ravaux, J. Lautru, J. Teisseire, I. Gozhyk, J. Jupille and R. Lazzari, Acta Mater., 2018, 143, $281-290$.

17 H. Liu, B. Wang, E. S. P. Leong, P. Yang, Y. Zong, G. Si, J. Teng and S. A. Maier, ACS Nano, 2010, 4, 3139-3146.

18 R. Lazzari and J. Jupille, Phys. Rev. B, 2005, 71, 045409.

19 G. Kästle, H. G. Boyen, B. Koslowski, A. Plettl, F. Weigl and P. Ziemann, Surf. Sci., 2002, 498, 168-174.

20 R. Cavallotti, H.-L. Thi Le, J. Goniakowski, R. Lazzari, J. Jupille, A. Koltsov and D. Loison, Phys. Chem. Chem. Phys., 2016, 18, 3032-3039.

21 H.-A. T. Le, J. Goniakowski, C. Noguera, A. Koltsov and J.-M. Mataigne, J. Phys. Chem. C, 2016, 120, 9836-9844.

22 H.-L. Thi Le, R. Lazzari, J. Goniakowski, R. Cavallotti, S. Chenot, C. Noguera, J. Jupille, A. Koltsov and J.-M. Mataigne, J. Phys. Chem. C, 2017, 121, 11464-11471.

23 H.-L. T. Le, J. Goniakowski, C. Noguera, A. Koltsov and J.-M. Mataigne, J. Phys. Chem. C, 2017, 121, 25143-25151.

24 M. Messaykeh, J. Goniakowski, G. Cabailh, J. Jupille, R. Lazzari, P. Lagarde and N. Trcera, J. Phys. Chem. C, 2019, 123, 29245-29254.
25 M. Messaykeh, S. Chenot, P. David, G. Cabailh, J. Jupille, A. Koltsov and R. Lazzari, Crystal Growth \& Design, 2021, 21, 3528-3539.

26 M. Guttmann, Reactive phase formation at interfaces and diffusion processes, 1994, pp. 527-548.

27 P. Drillet, Z. Zermout, D. Bouleau, J. Mataigne and S. Claessens, La Revue de Métallurgie-CIT, 2004, 101, 831837.

28 Z. Dai, P. Borghetti, S. Chenot, P. David, J. Jupille, G. Cabailh, J. Goniakowski and R. Lazzari, Appl. Surf. Sci., 2019, 492, 886-895.

29 Z. Dai, N. Alyabyeva, P. Borghetti, S. Chenot, P. David, A. Koltsov, G. Renaud, J. Jupille, G. Cabailh and R. Lazzari, Appl. Surf. Sci., 2020, 509, 145312.

30 Z. Dai, N. Alyabyeva, M. Van den Bossche, P. Borghetti, S. Chenot, P. David, A. Koltsov, G. Renaud, J. Jupille, G. Cabailh, C. Noguera, J. Goniakowski and R. Lazzari, Phys. Rev. Materials, 2020, 4, 074409.

31 E. Søndergård, O. Kerjan, D. Abriou and J. Jupille, Eur. Phys. J. D, 2003, 24, 343-345.

32 M. Yoshitake, S. Yagyu and T. Chikyow, J. Vac. Sci. Technol., A, 2014, 32, 021102.

33 B. Ealet, B. Robrieux and E. Gillet, J. Adhes. Sci. Technol., 1992, 6, 1221-1231.

34 H. Lu, D. H. Shen, C. L. Bao and Y. X. Wang, Physica Status Solidi (a), 1997, 159, 425-437.

35 M. Eriksson, J. Sainio and J. Lahtinen, J. Chem. Phys., 2002, 116, 3870-3874.

36 J. Sainio, M. Eriksson and J. Lahtinen, Surf. Sci., 2003, 532535, 396-401.

37 NIST X-ray photoelectron spectroscopy database, https://srdata.nist.gov/xps/Default.aspx.

38 S. Tougaard, Surf. Interface Anal., 1997, 25, 137-154.

39 J. Yeh and I. Lindau, At. Data Nucl. Data Tables, 1985, 32, $1-155$.

40 A. Jablonski, Surf. Sci., 2019, 688, 14-24.

41 R. Lazzari, J. Goniakowski, G. Cabailh, R. Cavallotti, N. Trcera, J. Jupille and P. Lagarde, Nano Lett., 2016, 16, 2574-2579.

42 B. Ravel and M. Newville, J. Synchrotron Rad., 2005, 12, 537541.

43 http://feff.phys.washington.edu/feffproject-references.html.

44 http://www.physik.de/mateck.

45 C. T. Campbell and S. M. Valone, J. Vac. Sci. Technol. A, 1985, 3, 408-411.

46 G. Renaud, B. Villette, I. Vilfan and A. Bourret, Phys. Rev. Lett., 1994, 73, 1825-1828.

47 P. Guénard, G. Renaud, A. Barbier and M. Gautier-Soyer, Surf. Rev. Lett., 1998, 5, 321.

48 G. Renaud, Surf. Sci. Rep., 1998, 32, 1-90.

49 P. E. Blöchl, Phys. Rev. B, 1994, 50, 17953-17979.

50 G. Kresse and J. Hafner, Phys. Rev. B, 1994, 49, 14251-14269.

51 G. Kresse and J. Furthmüller, Phys. Rev. B, 1996, 54, 11169- 
11186.

52 G. Kresse and J. Furthmüller, Comp. Mater. Sci., 1996, 6, 1550.

53 G. Kresse and J. Joubert, Phys. Rev. B, 1999, 59, 1758-1775.

54 J. Klimeš, D. R. Bowler and A. Michaelides, J. Phys.: Condens. Matter, 2010, 22, 022201.

55 J. Klimes, D. R. Bowler and A. Michaelides, Phys. Rev. B, 2011, 83, 195131.

56 V. I. Anisimov, F. Aryasetiawan and A. I. Liechtenstein, J. Phys.: Condens. Matter, 1997, 9, 767-808.

57 S. L. Dudarev, G. A. Botton, S. Y. Savrasov, C. J. Humphreys and A. P. Sutton, Phys. Rev. B, 1998, 57, 1505-1509.

58 L. Köhler and G. Kresse, Phys. Rev. B, 2004, 70, 165405.

59 V. Nilsson, M. Van den Bossche, A. Hellman and H. Grönbeck, Surf. Sci., 2015, 640, 59-64.

60 G. K. Wertheim, S. B. DiCenzo and S. E. Youngquist, Phys. Rev. Lett., 1983, 51, 2310-2313.

61 H. Hövel, B. Grimm, M. Pollmann and B. Reihl, Phys. Rev. Lett., 1998, 81, 4608-4611.

62 A. Howard, D. N. S. Clark, C. E. J. Mitchell, R. G. Edell and V. R. Dhanak, Surf. Sci., 2002, 518, 210-224.

63 E. Chernysheva, W. Srour, B. Philippe, B. Baris, S. Chenot, R. F. Duarte, M. Gorgoi, H. Cruguel, H. Rensmo, H. Montigaud, J. Jupille, G. Cabailh, S. Grachev and R. Lazzari, Phys. Rev. B, 2018, 97, 235430.

64 R. Lazzari, Igor Pro Paris Photoemission Package can be downloaded with a user guide from: http://www.insp.upmc.fr/I4P-Igor-Pro-ParisPhotoemission.html?lang $=$ en.

65 S. Doniach and M. Sunjic, Journal of Physics Part C : Solid State Physics, 1970, 3, 285-291.

66 C. Klauber, Surf. Interface Anal., 1993, 20, 703-715.

67 H. Kato, Y. Sakisaka, M. Nishijima and M. Onchi, Surf. Sci., 1981, 107, $20-30$.
68 E. Ünveren, E. Kemnitz, S. Hutton, A. Lippitz and W. E. S. Unger, Surf. Interface Anal., 2004, 36, 92-95.

69 I. Grohmann, E. Kemnitz, A. Lippitz and W. E. S. Unger, Surf. Interface Anal., 1995, 23, 887-891.

70 A. M. Salvi, J. E. Castle, J. F. Watts and E. Desimoni, Appl. Surf. Sci., 1995, 90, $333-341$.

71 A. R. Pratt and N. S. McIntyre, Surf. Interface Anal., 1996, 24, 529-530.

72 M. Aronniemi, J. Sainio and J. Lahtinen, Surf. Sci., 2005, 578, $108-123$.

73 J. Sainio, M. Aronniemi, O. Pakarinen, K. Kauraala, S. Airaksinen, O. Krause and J. Lahtinen, Appl. Surf. Sci., 2005, 252, 1076 - 1083.

74 R. P. Gupta and S. K. Sen, Phys Rev B, 1975, 12, 15-19.

75 M. C. Biesinger, B. P. Payne, A. P. Grosvenor, L. W. M. Lau, A. R. Gerson and R. S. C. Smart, Appl. Surf. Sci., 2011, 257, $2717-2730$

76 B. P. Payne, M. C. Biesinger and N. S. McIntyre, J. Electron Spectrosc. Relat. Phenom., 2011, 184, 29 - 37.

77 V. Coustet and J. Jupille, Il Nuovo Cimento, 1997, 19D, 16571664.

78 C. Niu, K. Shepherd, D. Martini, J. Tong, J. Kelber, D. R. Jennison and A. Bogicevic, Surf. Sci, 2000, 465, 163-176.

79 S. Chambers, T. Droubay, D. Jennison and T. Mattsson, Science, 2002, 297, 827-831.

80 Q. Fu, T. Wagner and M. Rühle, Surf. Sci., 2006, 600, 48704877.

81 A. Kelber, C. Niu, K. Shepherd, D. R. Jennison and A. Bogicevic, Surf. Sci., 2000, 446, 76-88.

82 J. Jupille, Reviews in Mineralogy \& Geochemistry, 2014, 78, 331-369.

83 D. P. Woodruff, Chem. Rev., 2013, 113, 3863-3886.

84 R. Lazzari and I. Simonsen, Thin Solid Films, 2002, 419, 124136. 